\title{
Occurrence of Geological Risks in the Development of Fractured Reservoirs
}

\author{
Boris Alexandrov ${ }^{1}$, Evgenia Zakharchenko ${ }^{2}$, Aslambek Elzhaev ${ }^{3}$, Ludmila Oks ${ }^{4}$ \\ Kuban State Agrarian University, 350040, Krasnodar, Russia \\ ${ }^{2}$ Kuban State University, 350040, Krasnodar, Russia \\ ${ }^{3}$ Grozny State Oil Technical University, 364051, Grozny, Russia \\ ${ }^{4}$ Rosneft oil company, 350000, Krasnodar, Russia
}

doi: https://doi.org/10.21467/abstracts.93.107

\begin{abstract}
A BST RA C T
In the current circumstances the efficient activity of the oil and gas companies depends not only on the size of investments, but also in a large extent on how reliably the enterprise estimates the prospects for its development. Uncertainty or lack of complete reliable information about reserves of developed deposits, their geological and technical characteristics, prices for hydrocarbon raw materials and other basic indicators, which are being used in the drafting and implementation of development projects and longterm plans of the enterprise development, leads to the fact that it is almost impossible to avoid risks. Therefore, studies aimed at identifying the most important risks that will be taken into account in the planning system will make it possible to ensure the correspondence between actual indicators correspond and their planned values.

At present, some Russian researchers have introduced the following classification of risk assessment of oil and gas production enterprises. Hazards of oil and gas companies are primarily grouped by sphere of occurrence and divided into arising in internal and external environments. In the external environment of oil and gas production enterprises, the following types of hazards systematically occur: credit and banking; market (commercial); currency; political; competitive; legislative; external economic; force majeur. In the internal environment of oil and gas companies, the following types of risks are identified - non- systematic in terms of repeatability: financial; institutional; marketing and technical. Also in the internal environment of oil and gas producers risks depend on internal and external factors. Internal factors include production, technological and environmental hazards, and external factors include natural and geological hazards.

Geological hazard characterizes insufficient level of knowledge of balance and recoverable reserves of oil and gas deposits, lack of geological exploration and geophysical information about reservoir properties of the formation, as a result of which there is a possibility of unsustainable development of the deposit and its earlier production. The main reasons for exceeding or non-fulfillment of indicators of long-term plans for production and sale of hydrocarbon raw materials of oil and gas producing enterprises are that the probability of economic losses due to incomplete study of geological and geophysical conditions of oil and gas fields development and reservoir properties of the formation, as well as insufficient information about balance and recoverable reserves (geological hazard) are not taken into account.

In this work we will focus on a more detailed geohazard assessment in the development of fractured carbonate manifolds. In real heterogeneous formations, the development of oil and gas deposits is significantly influenced by the type of reservoir, so it is very important to take into account the direction of development of the main fracture system when developing the deposit with the cracked reservoir and planning the system of arrangement of production and injection wells. Formation of fracture type of collector in carbonate thickness takes place not in a process of rock sedimentation, but mainly in a rock
\end{abstract}

(C) 2020 Copyright held by the author(s). Published by AIJR Publisher in "Abstracts of The Second Eurasian RISK-2020 Conference and Symposium" April 12- 19, 2020, Tbilisi, Georgia. Jointly organized by AMIR Technical Services LLC, Georgian Technical University, Institute of Geography (Kazakhstan) and Russian Institute of Petroleum Geology and Geophysics.

AijR DOI: $10.21467 /$ abstracts.93 
The Second Eurasian RISK-2020 Conference and Symposium

destruction at formation of the anticline fold. The tense state experienced by rocks in the Earth's crust arises as a result of various factors.

Therefore, in each particular case, various types of rupture disorders, which occur depending on the ratio of stresses, morphology of folds and other folding factors, have a significant impact. The relationships between the acting forces system and its accompanying stress system are very complicated. Nevertheless, studying the regularities of the structure of tectonic stress fields is necessary to understand the causes and conditions of development of folds and cracking of rocks.

The relationship between local rises and deep faults can be considered on the example of the upperCretaceous-lower-Paleocene complex of the Tersko-Sunzhen oil-and-gas bearing region, which are fault structures, the long axis of which is significantly higher than the transverse one. The most characteristic of these are Malgobek-Gorskaya, Khayan- Kortovskaya, Oktyabrskaya, Starogroznenskaya and other structures. They are characterized by maximum amplitude, large slope of wings and presence of longitudinal and diagonal violations such as surges and discharges. These folds were finally formed in postpliocene time due to the strong activation of tectonic processes, which resulted in the revival of deep fault zones and the manifestation of short-term upward block movements of the foundation. It can be assumed that the structures of the Tersko-Sunzhen oil and gas bearing region by genesis are folds of a mixed type: at first, they were folds of transverse bend, and then they finally formed under the action of a horizontal component as folds of longitudinal bend. The formed fold morphology controls the formed crack system, which must be taken into account especially during the development phase of the deposit. Morphological features of fold structure are determined by quantification of average value of secondary fracture porosity. Orientation of the main system of cracks depends on the nature of structure formation, and permeability of cracks is determined by their openess.

Therefore, the bulk of the oil and gas flow into the well and the bulk of the water injected into the injection well will occur in the direction of the prevailing crack system. The direction of the main system of cracks can be predicted at the initial stage of exploration on the basis of the results of geological and geophysical surveys carried out and the direction of the detected faults from the materials of seismic exploration, as well as to be specified from the materials of inclonometric surveys in the first drilled wells.

In order to effectively develop and further exploit complex-built crack-type collectors, it is necessary to take into account the direction of the main crack system, as well as to plan systems for the location of production and injection wells, considering directions of development of the crack systems. When assessing risks of development of oil and gas fields it is necessary to take into account the whole spectrum of risks, paying special attention to one of the important external factors - geological hazards. Geohazard assessment is a systematic assessment of geological uncertainties that have a major impact on the calculation of geological and recoverable reserves. 